\title{
Electrochemical studies on single-crystal aluminium surfaces
}

\author{
Grainne M. Treacy* and Carmel B. Breslin \\ Department of Chemistry, National University of Ireland, Maynooth, Co. Kildare, Ireland
}

(Received 30 May 1997; in revised form 8 July 1997)

\begin{abstract}
The electrochemical behaviour of single-crystal aluminium oriented in the (111), (110) and (100) directions in chloride- and indium-containing solutions was studied. It was found that the susceptibility of the single crystals to the onset of pitting attack in the chloride solution varied in the order $(111)>(110)>(100)$. This was evident from pitting potential and induction time data, where the most noble pitting potential values and the longest induction periods were recorded for the (100) surface. This was explained in terms of differences in the surface energy of (111), (110) and (100) planes. It was also found that cathodic reduction reactions (hydrogen evolution and oxygen reduction reactions) proceeded at a greater rate on the (100) surface. In addition, the time delay between the addition of indium ions to solution and the onset of activation of the immersed electrode by the indium species was shorter for the (100) surface. This was attributed to the more efficient incorporation of indium into the (100) lattice. (C) 1998 Elsevier Science Ltd. All rights reserved.
\end{abstract}

Key words: aluminium, single crystal, pitting, indium activation, cathodic reduction.

\section{INTRODUCTION}

Although the electrochemical behaviour and the initiation of pitting attack on aluminium surfaces has been studied for many years, little attention has been paid to the electrochemical behaviour, or the localized corrosion behaviour, of single crystal surfaces of aluminium.

There is evidence [1-14] to suggest that surface orientation has some influence on the initiation and/or propagation of localized attack on aluminium. Kaesche and co-workers [4-6] observed the propagation of microscopic crystallographic tunnels during the pitting of polycrystalline and (100) oriented aluminium in various halide solutions. They found the tunnel side walls to be lined with (100) faces and (110) faces in the case of pitting in iodide solution. Similar findings were reported by Alwitt et al. [7]. In earlier studies, by Galvele et al. [8], Payer and Staehle [9] and Metzger and Zahavi [10], faceted etch pits were observed on

*Author to who correspondence should be addressed. Present address: IPTME, Loughborough University, Loughborough, Leicestershire LE11 3TU, U.K. E-mail: cbreslin@may.ie polycrystalline aluminium exposed to chloride solutions. These facets were, again, considered to be (100) faces.

Consistent with these observations Arora and Metzger [11] found, on exposing polycrystalline aluminium to $\mathrm{HCl}$ solution, that the grain surfaces oriented near (111) planes corroded at much higher rates than those near (100) planes. Similar behaviour was observed for single crystal aluminium in acid solutions [12]. Although Feller et al. [13] did not observe any difference in the pitting potentials of (111), (110) and (100) faces on aluminium single crystals, Yasuda et al. [14] found that the pitting potentials varied in the order $E_{\text {pit }}(100)>E_{\text {pit }}(110)>E_{\text {pit }}(111)$. Furthermore, the pitting density was found to be highest on (111) oriented surfaces, where small clusters of small pits were observed.

In addition to the observed variations in the pitting characteristics of oriented aluminium electrodes, variations in the mechanism of oxide growth, in its initial stages, have been recorded. It would appear that the mode of oxygen chemisorption on (111), (110) and (100) oriented aluminium differs $[15,16]$. From studies using Atomic emission spectroscopy, AES, X-ray photoelectron spec- 
troscopy, XPS and low-energy electron diffraction, LEED [17], there is evidence that the oxidation of aluminium oriented in the (111) plane follows a two-stage process: oxygen atoms initially adsorb, as an ordered mono-layer followed by a slower uptake of oxygen to form an amorphous layer. For aluminium oriented in the (100) plane an amorphous oxide forms in a one-stage process. Aluminium oriented in the (110) plane appears to have an oxidation mechanism somewhat intermediate to both of these cases, however, the exact mechanism is unclear.

Such mechanisms of oxide growth may affect the manner in which aggressive ions interact with the metal at the metal/oxide interface. In this communication, the pit-initiation behaviour of (111), (110) and (100) oriented surfaces of aluminium in chloride solutions is described and discussed. In addition, the anodic and cathodic polarization behaviours of the electrodes was studied in chloride and indiumcontaining chloride electrolytes.

\section{EXPERIMENTAL}

Polycrystalline and single-crystal aluminium rods, of $99.9999 \%$ purity (prepared by Goodfellow Metals), were abraded carefully, using a specially designed holder, with suspensions of diamond paste to a mirror finish. The mechanically deformed layer was removed by electro-polishing the crystals in a $15 \%$ perchloric acid/ethanol solution at $-5^{\circ} \mathrm{C}$. These polishing procedures did not seem to alter the crystallographic orientation as evidenced from $\mathrm{X}$-ray diffraction measurements of the single crystals prior to and following the polishing regime. The electrodes were then rinsed in ethanol and distilled water, and mounted with resin so as to expose the circular crystal face, approximately $1 \mathrm{~cm}^{2}$ in area, to the test solution.

Test solutions consisted of $\mathrm{Na}_{2} \mathrm{SO}_{4}, \mathrm{NaCl}, \mathrm{NaBr}$, $\mathrm{In}_{2}\left(\mathrm{SO}_{4}\right)_{3} \cdot 5 \mathrm{H}_{2} \mathrm{O}$ and combinations of these salts. These were prepared using AnalaR grade reagents and distilled water. The $\mathrm{pH}$ of the $\mathrm{Na}_{2} \mathrm{SO}_{4}, \mathrm{NaCl}$ and $\mathrm{NaBr}$ solutions was adjusted to a $\mathrm{pH}$ of 7.0 using $\mathrm{H}_{2} \mathrm{SO}_{4}$ and $\mathrm{NaOH}$. The $\mathrm{pH}$ of the indiumcontaining solutions varied between 2.5 and 3.2, and was not altered due to the hydrolysis reactions of indium. The electrochemical cell consisted of a pyrex glass cell, a saturated calomel reference electrode and graphite auxiliary electrodes.

All electrochemical measurements were performed with a Model 263 potentiostat controlled by the Model 352 corrosion-measurement-software package. Potentiodynamic scans were carried out using a scan rate of $0.5 \mathrm{mV} \mathrm{s}^{-1}$. The scan was initiated at $-1600 \mathrm{mV}$ (SCE) and terminated at the pitting potential. The pitting potential was determined from these potentiodynamic scans as the potential at which the first current increases (on a scale of 100 $\mathrm{nA}$ ) could be observed. In potentiostatic activation studies, the test electrodes were passivated at an appropriate potential in the passive region for a 20 min period. Activating species were then added, the cell solution agitated and the current-time transients recorded. The induction period, $t_{\text {ind }}$, was deemed to be the time interval between the addition of the activating species and the onset of the current increase in the potentiostatic measurements (on a $100 \mathrm{nA}$ scale). For activation by chloride, the test electrodes were passivated in a $0.1 \mathrm{~mol} \mathrm{\textrm {dm } ^ { - 3 }}$ $\mathrm{Na}_{2} \mathrm{SO}_{4}$ solution at $-500 \mathrm{mV}$ (SCE). After the elapse of the $20 \mathrm{~min}$ passivation period a solution of $\mathrm{NaCl}$ was added to the working solution. The sulfate concentration was maintained at $0.1 \mathrm{~mol}$ $\mathrm{dm}^{-3}$. In the case of activation by indium, the test electrodes were polarized at $-1050 \mathrm{mV}$ (SCE) in a chloride solution. A solution of $\mathrm{In}_{2}\left(\mathrm{SO}_{4}\right)_{3} \cdot 5 \mathrm{H}_{2} \mathrm{O}$ in chloride was then added while maintaining a constant chloride concentration.

\section{RESULTS}

The potentiodynamic polarization plots for polycrystalline and single-crystal aluminium electrodes with (111), (110) and (100) faces, immersed in $0.5 \mathrm{~mol} \mathrm{dm}^{-3} \mathrm{NaCl}$ solutions are shown in Fig. 1. It can be seen that the cathodic and anodic polarization behaviour of the polycrystalline (111) and (110) surfaces appear similar, but that a significant increase in the rate of the cathodic reduction reactions occurs for the (100) surface. The average corrosion potentials, $E_{\text {corr }}$, recorded for the (111), (110) and (100) electrodes in this solution, averaged over 5 separate determinations, were $-(1263 \pm 89)$, $-(1326 \pm 141)$ and $-(1142 \pm 86) \mathrm{mV}$ (SCE), respectively, while the average corrosion current densities were $\quad(0.3 \pm 0.2), \quad(0.6 \pm 0.3) \quad$ and $\quad(1.0 \pm 0.6)$

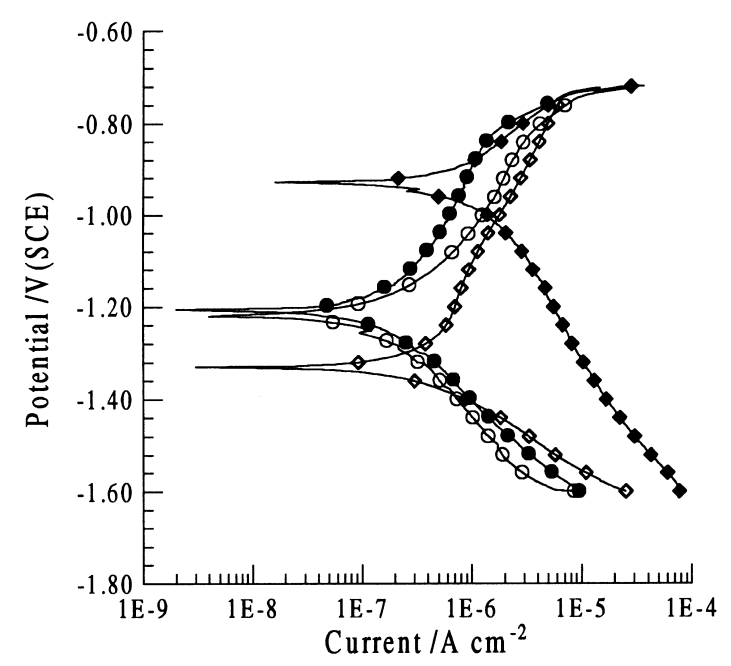

Fig. 1. The potentiodynamic polarization behaviour of aluminium $(99.9999 \%)$ oriented in the $\bigcirc(111), \diamond(110)$ and (100) direction and $\bullet$ polycrystalline phases in neutral $0.5 \mathrm{~mol} \mathrm{dm}{ }^{-3} \mathrm{NaCl}$ solution. 


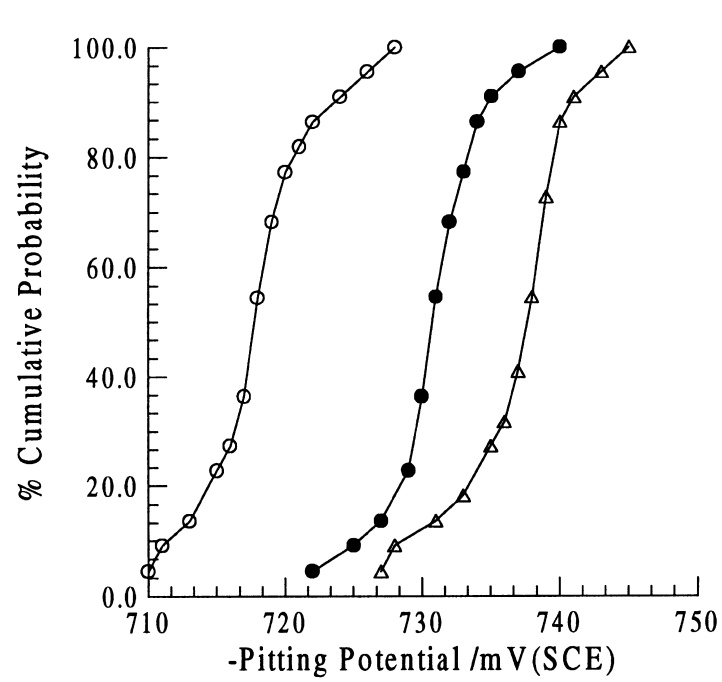

Fig. 2. The percentage cumulative probability as a function of the pitting potential for $\triangle(111), \quad(110)$ and $\bigcirc$ (100) single crystals of pure aluminium in neutral $0.5 \mathrm{~mol}$ $\mathrm{dm}^{-3} \mathrm{NaCl}$ solution.

$\mu \mathrm{A} \mathrm{cm}^{-2}$, respectively, where the indicated errors represent the greatest deviation from the given values. These data reflect the increase in the rate of the cathodic reduction reactions on the (100) surface.

The pitting potential showed a slight dependence on the crystal orientation. The pitting potentials recorded for a total of 22 separate determinations for the (111), (110) and (100) surfaces in a neutral $0.5 \mathrm{~mol} \mathrm{dm}^{-3} \mathrm{NaCl}$ solution are shown in Fig. 2. Here the pitting potentials are presented as a cumulative probability so that the number of samples, out of the 22 specimens, that have pitting potentials below a given value can be read directly from the $y$ axis. Even though there is little difference in some of the pitting potentials determined for the different crystal orientations, a clear clustering of the values occur, in which the (100) surface adopts the more noble pitting potentials $[-717 \pm 8 \mathrm{mV}$ (SCE)] and the (111) surface adopts the more active pitting potentials $[-737 \pm 8 \mathrm{mV}$ (SCE)]. These scatter bands represent the calculated standard deviations so that only a small difference in the susceptibility of the crystal planes to undergo pitting attack can be seen. The pitting potentials for polycrystalline aluminium, although not shown here, were similar to those of the (111) surface $[-735 \pm 10 \mathrm{mV}$ (SCE)].

A typical current-time profile for activation of the (100) single crystal in a chloride solution is shown in Fig. 3. Here, the electrode was passivated initially in a $0.1 \mathrm{~mol} \mathrm{dm} \mathrm{dm}^{-3} \mathrm{Na}_{2} \mathrm{SO}_{4}$ solution and then sufficient chloride was added to form a solution, $0.08 \mathrm{~mol} \mathrm{dm} \mathrm{dm}^{-3}$ in $\mathrm{NaCl}$, after a $20 \mathrm{~min}$ period. The onset of pitting corrosion is reflected by the ragged current increases which are observed after the elapse of a certain induction period. The general trend of an increasing current suggests that pit propagation is the dominant process and a number of well-developed pits could be observed following this active period. Owing to the statistical nature of pit initiation some distribution in these induction periods was found. A typical set of induction-time data is shown in Fig. 4 for the (111), (110) and (100) electrodes activated by a $0.1 \mathrm{~mol}$ $\mathrm{dm}^{-3} \mathrm{NaCl}$ solution. It can be seen that the distributions are skewed slightly so that the average values lie at slightly shorter induction periods. Such skewed-like distributions have been reported previously [18]. It is evident from these plots that shorter induction periods exist for the (111) single crystal electrode, while the (100) single crystal electrodes appear to be more resistant to the onset of localized attack, reflected by the longer induction periods.

It was possible to activate the aluminium electrodes at much more negative potentials by introducing indium ions into the test solution. A typical activation plot is shown in Fig. 5. Here, the aluminium electrode, polycrystalline, was polarized at $-1050 \mathrm{mV}$ (SCE) in a $0.5 \mathrm{~mol} \mathrm{dm} \mathrm{dm}^{-3} \mathrm{NaCl}$ solution and the current-time response recorded. After a 20 min period the indium salt solution was added to the electrolyte and the current-time behaviour was followed. The slight decrease in current obtained on addition of the indium solution was attributed to the lowering of the $\mathrm{pH}$ of the solution

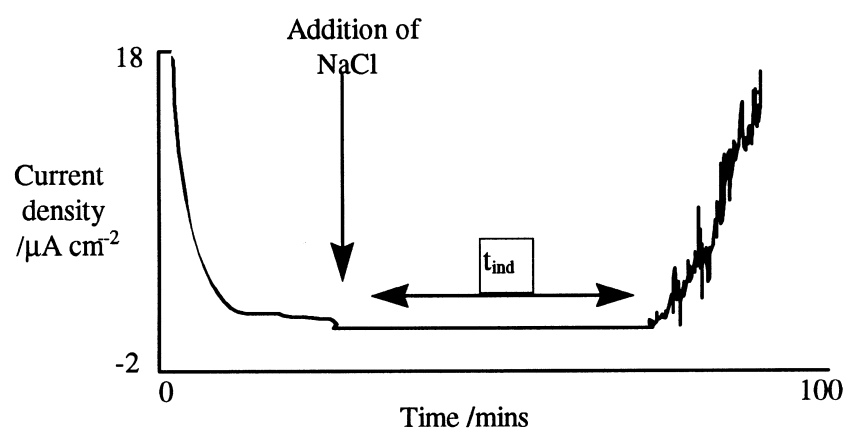

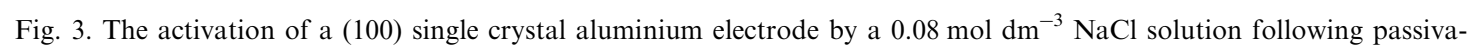
tion in $0.1 \mathrm{~mol} \mathrm{dm}{ }^{-3} \mathrm{Na}_{2} \mathrm{SO}_{4}$ solution for a $20 \mathrm{~min}$ period. 


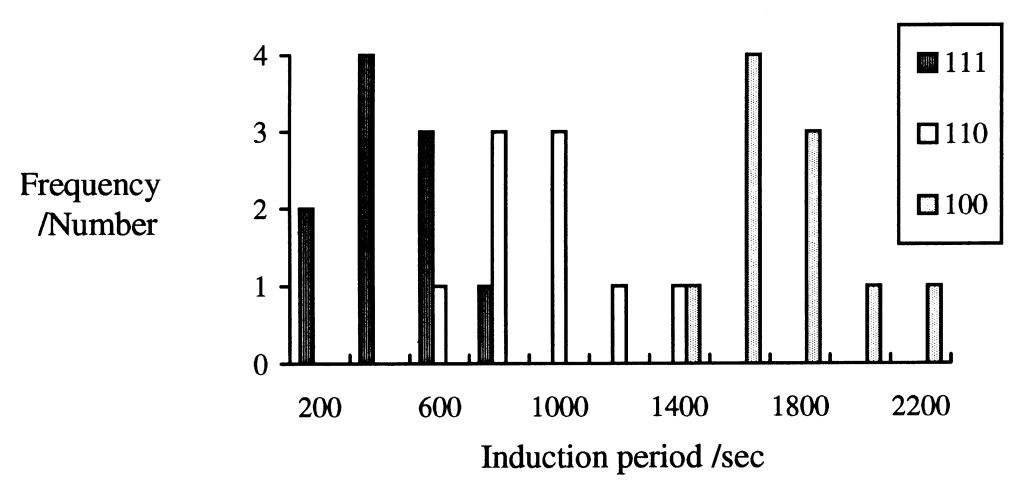

Fig. 4. Comparison of induction time, $t_{\text {ind }}$, for aluminium oriented in the (111), (110) and (100) directions polarized in $0.1 \mathrm{~mol} \mathrm{dm}^{-3} \mathrm{Na}_{2} \mathrm{SO}_{4}$ at $-500 \mathrm{mV}$ (SCE) to which $0.1 \mathrm{~mol} \mathrm{dm}^{-3} \mathrm{NaCl}$ was added after $20 \mathrm{~min}$.

and the deposition of indium onto the electrode surface [19]. After the elapse of a characteristic induction period, activation of the electrode occurred. The accompanying current fluctuations which are characteristic of recurring activation-repassivation events survive for a short period of time and then an irreversible increase in current is to be observed, indicating complete breakdown of the passive surface. SEM-EDAX examination of the electrode following such activation showed evidence of deep pitting. Some typical induction time data (averaged over at least four determinations) at two different indium salt concentrations for activation of the (111), (110) and (100) surfaces polarized at $-1050 \mathrm{mV}$ (SCE) are presented in Table 1, where the scatter bands shown represent the standard deviations. It can be seen that the induction periods depend on the concentration of the indium in solution, with activation occurring faster in the presence of the higher concentrations of dissolved indium, but the most significant finding is the much shorter induction periods required to activate the

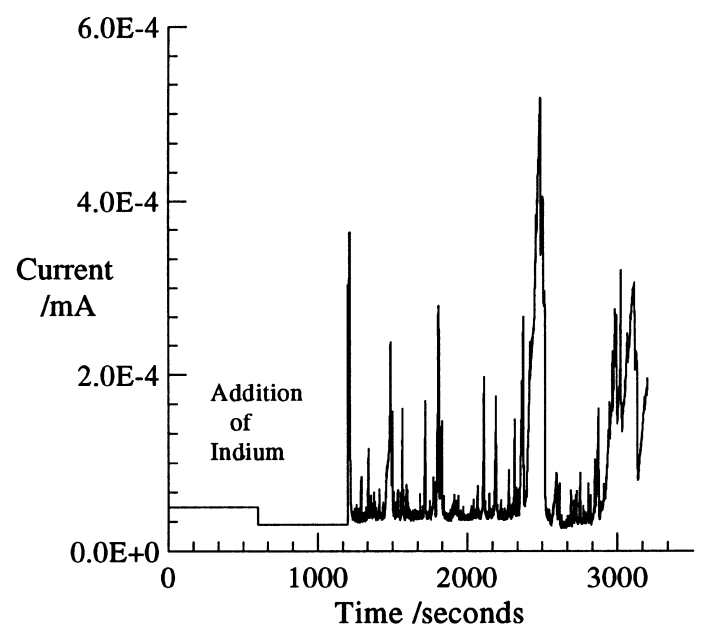

Fig. 5. The activation of $99.9999 \%$ aluminium polarized at

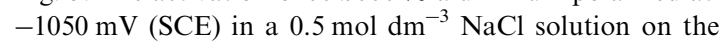
addition of $5 \times 10^{-3} \mathrm{~mol} \mathrm{dm}^{-3} \mathrm{In}_{2}\left(\mathrm{SO}_{4}\right)$
(100) face with the (111) and (110) faces having comparable induction periods. In addition, the induction periods recorded for polycrystalline aluminium were similar to those recorded for the (110) and the (111) surfaces indicating that the accelerated deposition of indium is seen only with the (100) surface.

\section{DISCUSSION}

It is seen from the results presented above that the electrochemical behaviour of the (100) crystal surface differs from that of both (110) and (111) in terms of both pit initiation and cathodic polarization behaviour. These differences are even more significant, given the fact that the most careful preparation of these surfaces will still introduce a number of defective sites and that the resulting crystal planes cannot be regarded as idealized (111), (110) and (100) surfaces.

Reduction reactions appear to occur at an appreciably higher rate on the (100) surface, as evident from Fig. 1. This suggests that the adsorption of dissolved $\mathrm{O}_{2}$ and $\mathrm{H}^{+}$occurs more readily on such surfaces. It can also be deduced from the induction periods measured in the indium-containing solutions, Table 1, that more efficient reduction of $\mathrm{In}^{3+}$ to metallic indium takes place at the (100) surface, as it is generally accepted that the first step in the activation of aluminium by indium ions in solution is the reduction of $\mathrm{In}^{3+}$ to $\mathrm{In}$ [19].

These variations appear to be related to the difference in the crystallographic structure of the (111), (110) and (100) faces as shown in Fig. 6 where the atomic structures of idealized (111), (110) and (100) surface planes of aluminium are presented in the manner used by Martinson and Flodström [17] with the likely sites for adsorption identified. It can be seen that the (111) surface is the most densely packed crystal face with two kinds of adsorption sites, designated as A and B. A represents a three-fold site over an atom in the second substrate layer, while B indicates a three-fold site over a hole in the second layer. $\mathrm{Al}(100)$ has the 
least packed surface of the three faces and has a four-fold adsorption site C. There is the possibility of penetration through this four-fold site, which is not possible for (111) and (110) surfaces. This may account for the much faster induction periods recorded for activation of the (100) surface with indium, where diffusion of metallic indium into the (100) surface is more likely. It appears also that adsorption of $\mathrm{O}_{2}$ and $\mathrm{H}^{+}$proceeds more efficiently at this more open (100) surface. It has been shown by Armstrong and Braham [20], from impedance measurements, that the passive layer is only approximately one mono-layer thick at cathodic potentials similar to those used here. Thus, it seems reasonable to assume that the crystallography of the underlying faces will play some role in the cathodic reduction reactions.

It also seems appropriate to attempt to explain the difference in the susceptibility of the (110) and (111) crystal faces to localized attack in terms of processes which occur at the metal/oxide interface and the crystallographic nature of the faces. The surface energy of these principal crystal faces differ by some $15 \mu \mathrm{J} \mathrm{cm}^{-2}$ in the order $(100)>(110) \approx(100)[21,22]$, which implies that the resistance of the planes towards dissolution varies in the order $(111) \approx(110)>(100)$. The formation of a pit on the (100) surface requires the dissolution of (111) subsurface atoms, while pit formation on the (111) surface requires the removal of the less tightly bound (100) subsurface atoms. Qualitatively, this difference accounts for the observed order of pit activation on the crystal surfaces where the ennoblement of the dissolution process, as in the case of the (100) surface, requires higher potentials to achieve a given current density and maintain active dissolution conditions and thus slightly more noble pitting potentials are measured. This type of an explanation is also consistent with the fact that (100) planes are observed during the pitting corrosion of polycrystalline aluminium which is predominantly oriented in the (111) direction. In this case pitting corrosion proceeds through the dissolution of the (100) subsurface atoms to give rise to the formation of tunnels. When these tunnels are viewed or stop propagating then they appear bounded by (100) walls. This explanation supports the idea that dissolution of the substrate material dominates the pitting process rather than the nature of the oxide films [23].

Table 1.

\begin{tabular}{lrrr}
\hline $\begin{array}{c}3 \\
{\left[\mathrm{In}^{3+}\right](\mathrm{mol}} \\
\left.\mathrm{dm}^{-3}\right)\end{array}$ & $(100)$ & \multicolumn{1}{c}{$(110)$} & \multicolumn{1}{c}{$(111)$} \\
\hline 0.010 & $5 \pm 3$ & $50 \pm 12$ & $30 \pm 15$ \\
0.006 & $15 \pm 8$ & $200 \pm 30$ & $180 \pm 30$ \\
\hline
\end{tabular}

An alternative explanation, which is also consistent with the apparent increased resistance to pitting attack of the (100) surface, involves using the point defect model to describe the onset of pitting attack [24]. According to this mechanism, solution anions are absorbed into anion vacancies in the passive film which then leads to the formation of a Schottky pair. Overall there is an enrichment of the concentration of cation vacancies on the oxide/solution interface which upon transport through the surface film can lead to mechanical instability of the film and the onset of pitting corrosion. The onset of pitting attack is determined by the parameters $J_{c a}$, which represents the transport of cation vacancies through the film, $J_{\mathrm{m}}$, which represents the rate of annihilation of the cation vacancies into the metal substrate and $\xi$, which represents the critical concentration of vacancies for mechanical instability, in accordance with the equation:

$$
\left(J_{\mathrm{ca}}-J_{\mathrm{m}}\right)\left(t_{\mathrm{ind}}-\tau\right)>\xi .
$$

In the cases of the principal crystalline surfaces of aluminium, (100), (110) and (111), it would appear that differences in the values of the parameter $J_{\mathrm{m}}$ can account for the differences observed in the susceptibility of the crystal planes towards pit initiation.

It can be seen from Fig. 6 that oxygen penetration of the metal lattice site $\mathrm{C}$ is possible only

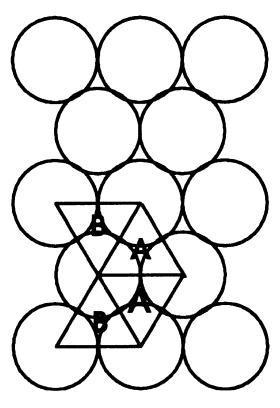

(110)

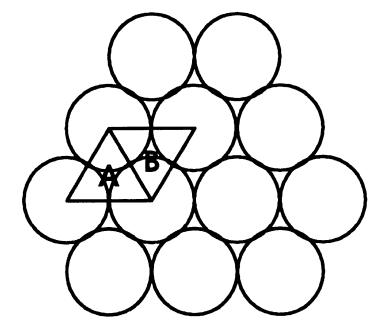

(111)

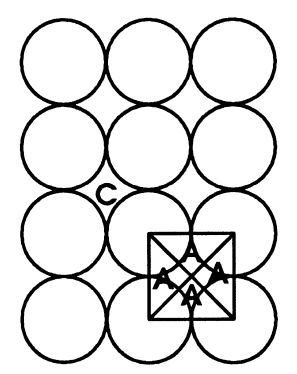

(100)

Fig. 6. Hard-sphere models for (111), (110) and (100) faces of aluminium with absorption sites A, B and C identified according to Martinson and Flodström [17]. 
in the case of the (100), to some extent in the case of (110) and not at all in the case of the most densely packed (111) surface of the metal on which bridged chemisorption sites of local three-fold symmetry dominate. Given the possibility of strong lateral ionic bonding effects of this first layer of the metal/oxide interface [25] when sites of type $\mathrm{C}$ are occupied by oxygen, it is to be expected that the parameter $J_{\mathrm{m}}$, should decrease in the order $J_{\mathrm{m}}(100)>J_{\mathrm{m}}(110) \gg J_{\mathrm{m}}(111)$. Annihilation of negatively charged cation vacancies at the metal/film interface will be inhibited by the negative field of the bridged oxygen ad-atoms in the cases of the (111) and, to a lesser extent, the (110) surfaces compared with the direct access to surface aluminium ions found on the (100) surface. Since the oxide forming the barrier film is amorphous the other parameters in the above equation are likely to be of similar magnitudes, which require that $t_{\text {ind }}$ should increase in the order $t_{\text {ind }}(111)<t_{\text {ind }}(110)$ $<t_{\text {ind }}(100)$ as can be observed from the results presented in Fig. 5. Although this mechanism accounts for the differences in the pit initiation of the single crystal planes it does not account for the observed crystallographic tunnel-like attack observed on aluminium. Nevertheless, both mechanisms may operate with the actual pit initiation event being more difficult on the (100) surface and the subsequent pit propagation step being less energetically favoured on the (100) surface.

\section{CONCLUSIONS}

Differences in the electrochemical behaviour of (111) and (100) surfaces are reported. It was found that the (111) surface was more susceptible to the onset of pitting attack in chloride-containing solutions. Cathodic reduction reactions appeared to occur more readily on the (100) surface. This included the reduction of dissolved oxygen and the reduction of $\mathrm{In}^{3+}$ to metallic indium. These effects are explained in terms of the crystallography of the crystal planes. Pit propagation on the (111) surfaces requires the dissolution of subsurface (100) atoms, whereas pit propagation on the (100) surface requires the dissolution of the more tightly bound (111) subsurface atoms, making the (100) crystal face more resistant to pitting attack. The more open arrangement of atoms on the (100) surface fa- cilitates reduction reactions and the incorporation of metallic indium into the (100) lattice.

\section{REFERENCES}

1. B. Yan, E. Youngs, G. C. Farrington and C. Laird, Corros. Sci. 26, 121 (1986).

2. S. M. Mayanna and T. H. V. Setty, Corros. Sci. 14, 691 (1974).

3. M. Janik-Czachor and Z. Szklarska-Smialowska, Corros. Sci. 8, 215 (1968)

4. M. Baumgartner and H. Kaesche, Werkstoffe Korros. 42, 158 (1991).

5. H. Kaesche, Werkstoffe Korros. 39, 152 (1988).

6. M. Baumgartner and H. Kaesche, Corros. Sci. 29, 363 (1989).

7. R. S. Alwitt, T. R. Beck and K. Herbert, Proc. 2nd International Conference On Localised Corrosion, NACE-9, Houston, TX, p. 165 (1987).

8. J. R. Galvele, S. M. de Micheli, I. L. Muller, S. B. de Wexler and I. L. Alanis, Localized Corrosion, (Edited by R. W. Staehle, B. F. Brown, J. Kruger and A. Agrawal) p. 580, NACE, Houston, TX (1974).

9. J. H. Payer and R. W. Staehle, Corrosion Fatigue, (Edited by O. F. Devereux, A. J. McEvily and R. W. Staehle) p. 211, NACE, Houston, TX (1972).

10. M. Metzger and J. Zahavi Passivity in Metals. (Edited by R. P. Frankenthal and J. Kruger), NACE, Houston, TX, p. 960 (1978).

11. O. P. Aora and M. Metzger, Proceedings 4th International Congress on Metallic Corrosion, NACE, Houston, TX, p. 435 (1969).

12. T. H. Orem, J. Res. Nat. Bur. Stand. 58, 57 (1957).

13. H. G. Feller, H. Heinrich, N. Kanani, R. Klinger and W. Laub, Aluminium 59, 138 (1983).

14. M. Yasuda, F. Weinberg and D. Tromas, $J$. Electrochem. Soc. 137, 3708 (1990).

15. C. W. B. Martinson, L. G. Peterson, S. A. Flodström and S. B. M. Hagström. Proc. Int. Photoemmision Symp. ESA SP. 118177 (1976).

16. P. O. Gartland, Surf. Sci. 62, 183 (1977).

17. C. W. B. Martinson and S. A. Flodström, Surf. Sci. 80, 306 (1979).

18. T. Shibata, Trans. ISIJ 23, 785 (1983).

19. W. M. Carroll and C. B. Breslin, Corros. Sci. 33, 7, 1161 (1992).

20. R. D. Armstrong and V. J. Braham, Corros. Sci. 38, 9 (1996).

21. J. Schochlin, K. P. Bohen and K. M. Ho, Surface Sci. 324, 133 (1995)

22. K. M. Ho and K. P. Bohen, Phys. Rev. Lett. 56, 934 (1985).

23. G. S. Frankel, R. C. Newman, C. V. Jahnes and M. A. Russak, J. Electrochem. Soc. 140, 2192 (1993).

24. D. D. Macdonald, J. Electrochem. Soc. 139, 3434 (1992).

25. I. P. Batra and S. Ciraci, Phys. Rev Lett. 39, 884 (1977). 